\title{
On the correlation between P300 amplitude and latency
}

\author{
JOHN POLICH \\ Scripps Clinic, La Jolla, California
}

\begin{abstract}
The relationship between P3(00) amplitude and latency across subjects, trial blocks, and task conditions was examined in two studies. Experiment 1 used a simple auditory discrimination task and obtained P3 values from two independent blocks of target stimulus trials. Experiment 2 employed an auditory discrimination paradigm in which task difficulty was manipulated within the same subjects. P3 amplitude and latency were correlated negatively across trial blocks and as task discrimination difficulty changed. These findings suggest that some variation in P3 amplitude and latency stems from the inherent association of these measures, such that individuals with larger components generally produce earlier peaks and vice versa.
\end{abstract}

The P300, or P3, component of the event-related brain potential (ERP) is generated when subjects attend and discriminate stimulus events that differ from one another on some dimension (Pritchard, 1981). A large body of evidence suggests that changes in P3 amplitude reflect memory-updating processes that operate to refresh an internal mental model of the environment (Donchin \& Coles, 1988; Donchin, Karis, Bashore, Coles, \& Gratton, 1986). This theoretical interpretation has been supported by a variety of studies that have demonstrated changes in P3 amplitude and latency associated with differential memory performance between experimental conditions (Johnson, Pfefferbaum, \& Kopell, 1985; Paller, McCarthy, \& Wood, 1988), as well as individual variation in normal and impaired memory function (Brown, Marsh, \& LaRue, 1982; Ladish \& Polich, 1989; Polich, Howard, \& Starr, 1983; Polich, Ladish, \& Bloom, 1990). Because depth-electroderecording studies in humans suggest that at least some portion of the P3 is generated in the medial temporal lobe, most likely including the hippocampus and amygdala structures-brain areas associated with learning and memory (Halgren et al., 1980; McCarthy, Wood, Williamson, \& Spencer, 1989), these findings imply that individual differences in P3 amplitude and latency indicate biological differences in information-processing capability.

Despite the importance of amplitude and latency values for the studies supporting this conclusion, the possible association between these two dependent measures has not been well characterized (cf. Fabiani, Gratton, Karis, \& Donchin, 1987; Michaelewski, Prasher, \& Starr, 1986). In a study designed to assess normative P3 variation, Polich (1986a) employed an auditory discrimination paradigm to elicit ERPs in a large, homogeneous sample $(N=100)$ and found that P3 amplitude and latency were

This work was supported by the Armstrong McDonald Foundation and NIAAA Grant AA06420. It is Publication 5257BCR from the Research Institute of Scripps Clinic. Address correspondence to J. Polich, Department of Neuropharmacology (BCR1), Research Institute of Scripps Clinic, 10666 N. Torrey Pines Road, La Jolla, CA 92037. correlated negatively at the $\mathrm{Fz}, \mathrm{Cz}$, and $\mathrm{Pz}$ electrode sites, with correlation coefficients of $-.11,-.28$, and -.32 , respectively-results that imply that individuals who produce large components do so relatively quickly compared with individuals who produce smaller components. If this relationship obtains when component amplitude and latency change across trial blocks (Kramer, Schneider, Fisk, \& Donchin, 1986; Polich, 1989a) or because of experimental manipulations (Johnson \& Donchin, 1978; Polich, 1987), then the correlation between these attributes may be an inherent property of the P3-perhaps related to the size and/or orientation of its neurophysiological generator (Pfefferbaum \& Rosenbloom, 1987; Polich, 1989b; Polich \& Burns, 1987).

\section{EXPERIMENT 1}

\section{Method}

Subjects. A total of 72 undergraduate students from the University of California, San Diego (mean age $=20.7, S D=2.1$ years) served as subjects for course credit. Equal numbers of each gender were employed, and all subjects reported being free of neurological or psychiatric disorders.

Recording conditions. ERPs were elicited with binaural 1000 - and $2000-\mathrm{Hz}$ tones present at $60 \mathrm{~dB}$ with a $9.9 \mathrm{rise} / \mathrm{fall}$ and $50-\mathrm{msec}$ plateau times. The tones were presented in a random series once every $2 \mathrm{sec}$. EEG activity was recorded at the $\mathrm{Fz}, \mathrm{Cz}$, and $\mathrm{Pz}$ electrode sites of the 10-20 system using gold-plated electrodes affixed with electrode paste and tape, referred to linked earlobes with a forehead ground. Additional electrodes were placed at the outer canthus and supraorbitally to the left eye, with a bipolar recording made of electro-ocular (EOG) activity. Impedance for all recording sites was $10 \mathrm{k \Omega}$ or less. The filter bandpass was .5 to $30 \mathrm{~Hz}$ ( $3 \mathrm{~dB}$ down, $12 \mathrm{~dB}$ octave/slope). The EEG was digitized at $1.5 \mathrm{msec}$ per point for $768 \mathrm{msec}$ with a $75-\mathrm{msec}$ prestimulus baseline. Trials on which the EEG or EOG exceeded $\pm 45 \mu \mathrm{V}$ were rejected automatically.

Procedure. Each subject completed two different trial blocks in which the target stimulus was presented randomly with a .20 probability. The subjects were required to move the index finger of the right hand whenever they detected the target tone, and the experimenter kept a record of the number of errors. Twenty artifact-free target-tone trials were obtained in each block (Polich, 1986b), with approximately $2 \mathrm{~min}$ elapsing between blocks.

Component measurement. Waveforms from each electrode for each condition were analyzed in the same fashion: the largest positive-going 

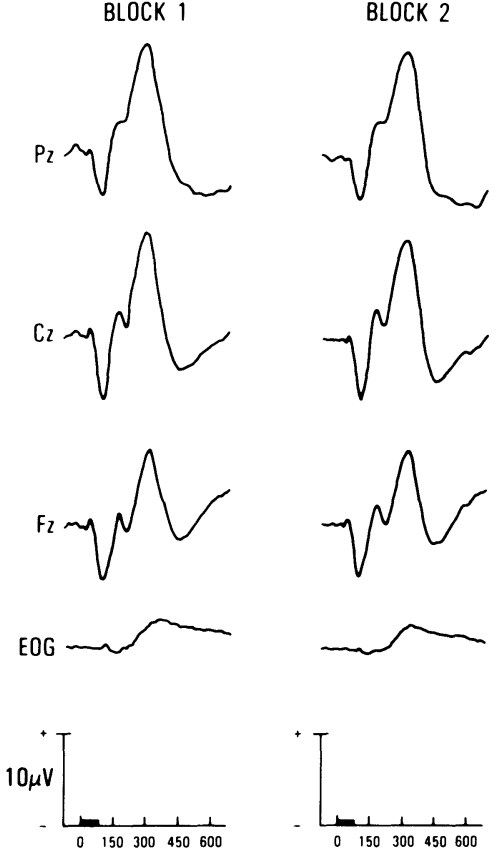

Latency (msec)

Figure 1. Superaverages $(n=72)$ from each electrode and trial block of Experiment 1.

peak occurring for all three electrode sites between 250 and $400 \mathrm{msec}$ was designated as the $\mathrm{P} 3$ component. The $\mathrm{N} 1, \mathrm{P} 2$, and $\mathrm{N} 2$ components were assessed at the $\mathrm{Cz}$ electrode as the largest component within the latency windows of 80-120, 100-200, and 160-240 msec, respectively. Amplitude was measured relative to the prestimulus baseline, and peak latency was defined as the time point of maximum positive amplitude. All analyses of variance (ANOVAs) employed Geisser-Greenhouse corrections for repeated measures designs.

\section{Results}

P3 amplitude and latency. Task performance was virtually perfect, with fewer than $0.6 \%$ of the target trials misperceived and no differences between trial blocks or subject sex obtained ( $F<1$ in both cases). The grand averaged ERPs taken across all subjects for each trial block and electrode are presented in Figure 1. The scattergrams, correlation coefficients, and probabilities for the relationship between P3 amplitude and latency are presented in Figure 2.

A three-factor (trial block $\times$ gender $\times$ electrode) ANOVA applied to the $P 3$ amplitude data revealed the usual increase from the frontal to parietal electrode sites $[F(2,140)$ $=100.8, p<.001]$ and an interaction between trial block and electrode such that Trial Block 2 amplitudes were smaller relative to Trial Block 1 for all but the parietal electrode site $[F(2,140)=3.9, p<.05]$. The same analysis applied to the P3 latency data found the usual decrease in latency from the frontal to parietal electrode sites $[F(2,140)$ $=23.5, p<.001]$ and an interaction between gender and electrode site such that female subjects tended to produce somewhat shorter latencies at the parietal site relative to male subjects $[F(2,140)=4.0, p<.05]$.

N1, P2, N2 components. The amplitude and latencies of the N1, P2, and N2 components also were assessed with correlational procedures for each trial block. The correlations (and probabilities) for Trial Blocks 1 and 2, respectively, were: $\mathrm{N} 1$ with $-.09(.24)$ and $.24(.02)$; $\mathrm{P} 2$ with .37 (.001) and $.41(.002)$; $\mathrm{N} 2$ with $.23(.03)$ and .42 (.001). A two-factor (trial block $\times$ gender) ANOVA applied to each component's data revealed that only P2 amplitude increased from Trial Block 1 to Trial Block 2 $[F(1,70)=5.9, p<.02]$.

\section{Discussion}

The data indicate that P3 amplitude and latency are negatively correlated for both trial blocks across electrodes in the same fashion and degree as observed previously (Polich, 1986a). The relationships obtained for the N1, P2, and N2 potentials were opposite in direction. Given the relatively consistent pattern of effects observed, it is reasonable to conclude that the negative association between $\mathrm{P} 3$ amplitude and latency is a reliable biological phenomenon across measurement occasions.

\section{EXPERIMENT 2}

If the correlation between P3 amplitude and latency is a biological aspect of component production, then the same sort of relationship should be observed if task conditions vary. The second study was conducted to test this possibility by collecting ERPs under separate conditions
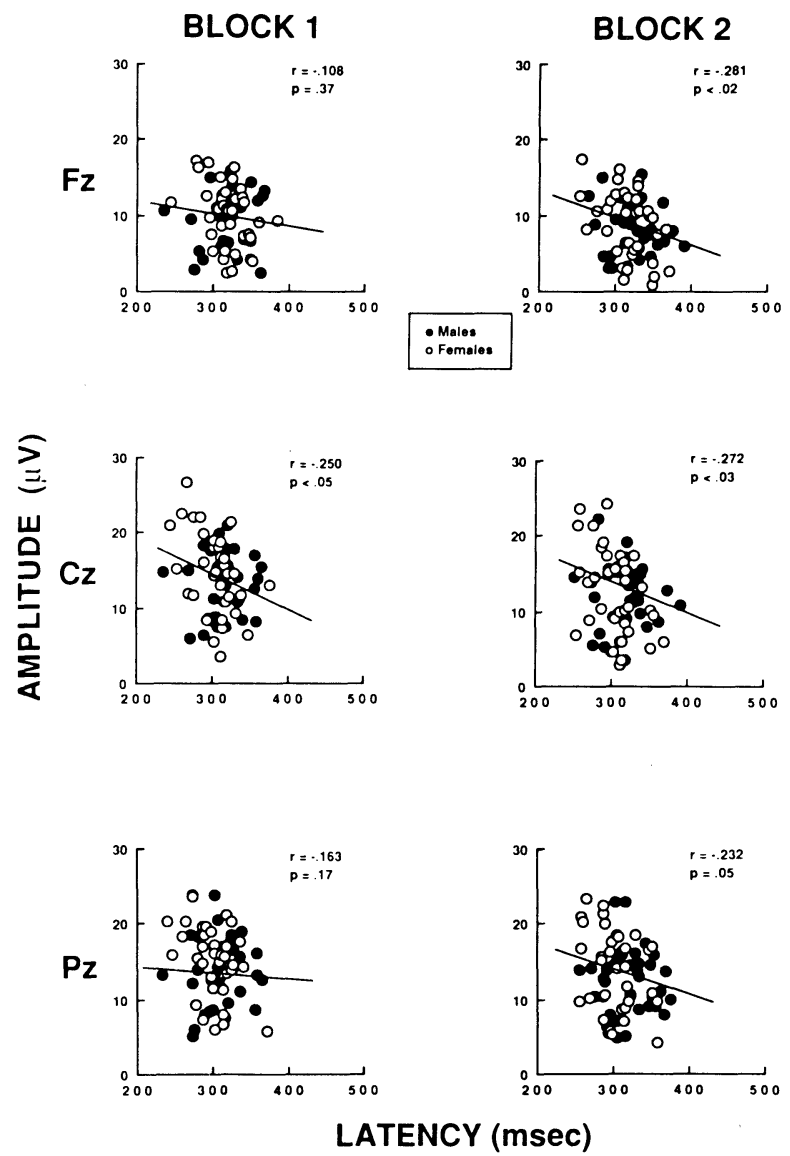

Figure 2. Scattergrams, correlation coefficients, and probabilities for P3 amplitude and latency from each electrode and trial block of Experiment 1. 


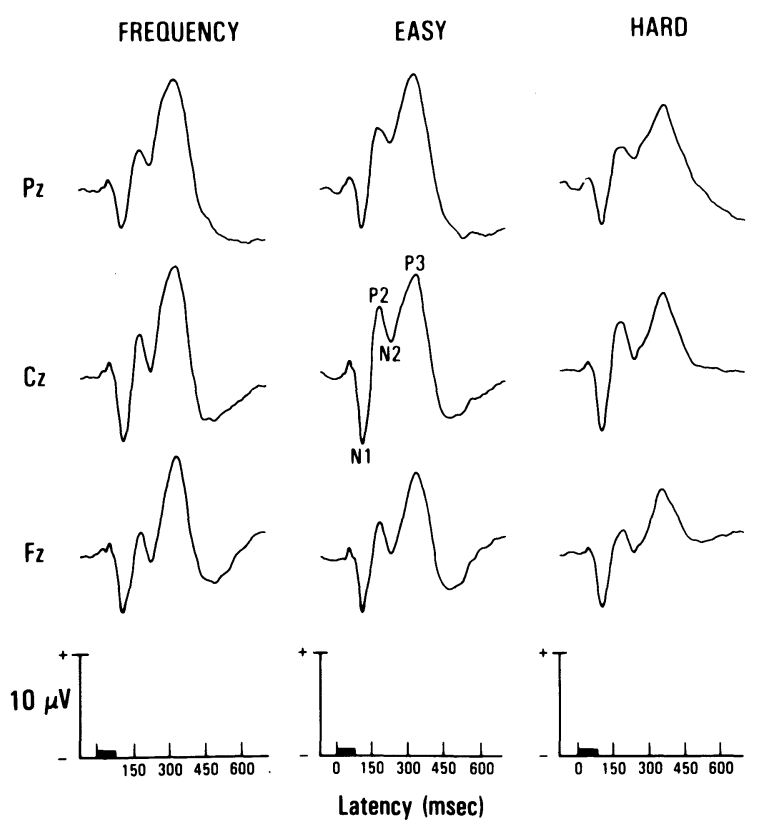

Figure 3. Superaverages $(n=88)$ from the frequency, easyintensity, and hard-intensity task conditions of Experiment 2. in which task difficulty was varied in order to change amplitude and latency values.

\section{Method}

A total of 88 undergraduate students (48 males, 40 females) from the University of California, San Diego (mean age $=21.1, S D=1.8$ years) served as subjects for course credit in the manner reported above. The recording conditions were identical to those employed in Experiment 1 except that each subject participated in three different task situations designed to assess P3 amplitude and latency changes due to stimulus discrimination difficulty (Polich, 1987). ERPs were elicited with binaural 1000 - and $2000-\mathrm{Hz}$ tones with a $9.9 \mathrm{rise} / \mathrm{fall}$ and $50-\mathrm{msec}$ plateau times. The frequency discrimination task consisted of 1000 - and $2000-\mathrm{Hz}$ tones at $60 \mathrm{~dB} \mathrm{SPL}$ with .80 and .20 probabilities, respectively, and was performed first. The easy-intensity task consisted of a series of $1000-\mathrm{Hz}$ tones such that .80 were $40 \mathrm{~dB}$ SPL and .20 were $60 \mathrm{~dB}$ SPL, with the latter occurring randomly throughout the sequence and designated as the target tone. The hard-intensity task consisted of $1000-\mathrm{Hz}$ tones presented in a series such that .80 were $40 \mathrm{~dB}$ and .20 were $45 \mathrm{~dB}$, with the latter occurring randomly throughout the series and designated as the target tone. The order of the easy and hard task presentations was counterbalanced across subjects, with practice trials presented before each condition to ensure accurate performance.

\section{Results}

P3 amplitude and latency. Task performance for the frequency and easy-intensity discrimination tasks demonstrated that fewer than $0.5 \%$ of the target trials were mis-

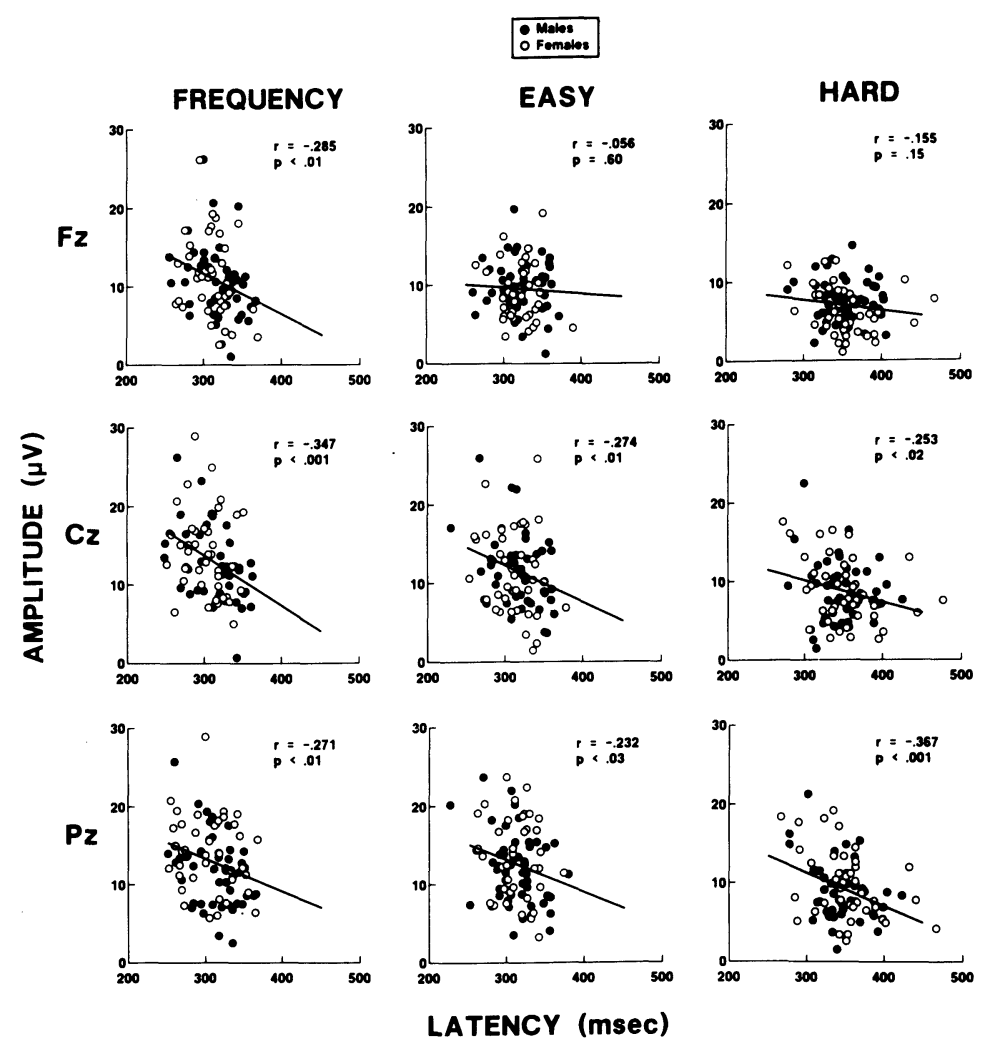

Figure 4. Scattergrams, correlation coefficients, and probabilities for $\mathbf{P 3}$ amplitude and latency from each electrode and task condition of Experiment 2. 
perceived, with the hard-intensity discrimination task yielding a mean of 1.8 errors. However, no significant differences were obtained between task conditions $[F(1,78)$ $=1.8, p>.15$ ], nor were any performance differences found between the male and female subjects $(p>.50)$. The grand averaged ERPs for each condition and electrode are presented in Figure 3. The scattergrams, correlation coefficients, and probabilities for P3 amplitude and latency at each electrode and condition are presented in Figure 4.

A three-factor (task condition $\times$ gender $\times$ electrode) ANOVA was performed on the amplitude and latency values obtained for each component from each subject. P3 amplitude demonstrated an overall decline as task difficulty increased $[12.3,11.2$, and $8.3 \mu \mathrm{V} ; F(2,172)=47.9$, $p<.001]$, while $\mathrm{P} 3$ latency increased $[311,317$, and $353 \mathrm{msec} ; F(2,172)=89.0, p<.001]$. The usual increase in amplitude and decrease in latency across electrode position also was obtained for both these measures $(p<.001)$. No other effects or interactions were obtained.

N1, P2, N2 components. The correlation coefficients (and probabilities) for the frequency, easy, and hard tasks, respectively, were: $\mathrm{N} 1$ with $-.02(.87),-.17(.12)$, and .04 (.72); P2 with .26 (.01), .26 (.01), and .01 (.94); N2 with .08 (.46), $.05(.68)$, and -.16 (.15). A one-way (task condition) ANOVA found significant effects for $\mathrm{P} 2$ and $\mathrm{N} 2$ amplitude ( $p<.001$ in both cases), with differences between task conditions also observed for P2 and N2 latency ( $p<.005$ in both cases).

\section{Discussion}

The negative correlations between P3 amplitude and latency portrayed in Figure 4 imply that amplitude and latency are related systematically, and their association is strongest when measured at the central/parietal scalp locations as found previously (the present Experiment 1; Polich, 1986a). Even though overall $P 3$ amplitude and latency did change across the task-difficulty conditions, the negative relationship between these two measures was maintained. Thus, the correlational results from Experiment 2 again suggest that the association between $\mathrm{P} 3$ amplitude and latency across individuals appears to be a fundamental attribute of neurophysiological processes.

\section{GENERAL DISCUSSION}

The findings of the present studies indicate that $\mathrm{P} 3$ amplitude and latency are negatively correlated across individual subjects. The lack of similar effects for the N1, P2, and N2 components suggests that this relationship is manifested primarily in the $\mathrm{P} 3$ component. Although the basic reason for such an association is not clear, it seems reasonable to suppose that large amplitude P3 components reflect the electrical activity of large numbers of neurons, such that the more activity a given individual produces, the shorter the latency of the P3-at least for the auditory stimuli and finger-tap discrimination tasks used here. This relationship may be inherent in the nature of the generating mechanism(s) of the P3 component (Halgren et al., 1980; McCarthy et al., 1989). Although such factors as head size, skull thickness, and so forth, contribute to P3 values (Pfefferbaum \& Rosenbloom, 1987; Polich, 1989b; Polich \& Burns, 1987), studies comparing multiple measures from the same subjects find good reliability between trials (Fabiani et al., 1987; Polich, 1986a; Sklare \& Lynn, 1984). Thus, within the limits of variability imposed by extracerebral sources, an individual's P3 amplitude and latency are fairly consistent and suggest that biological factors are a primary determinant of overall individual P3 morphology.

\section{REFERENCES}

Brown, W. S., Marsh, J. T., \& LARue, A. (1982). Event-related potentials in psychiatry: Differentiating depression and dementia in the elderly. Bulletin of the Los Angeles Neurological Society, 47, 91-107.

Donchin, E., \& Coles, M. G. H. (1988). Is the P300 component a manifestation of context updating? Brain \& Behavioral Sciences, 11, 357-374.

Donchin, E., Karis, D., Bashore, T. R., Coles, M. G. H., \& GratTON, G. (1986). Cognitive psychophysiology and human information processing. In M. G. H. Coles, E. Donchin, \& S. W. Porges (Eds.), Psychophysiology: Systems, processes, and applications (pp. 244-267). New York: Guilford.

Fabiani, M., Gratton, G., Karis, D., \& Donchin, E. (1987). The definition, identification, and reliability of measurement of the P300 component of the event-related brain potential. In P. K. Ackles, J. R. Jennings, \& M. G. H. Coles (Eds.), Advances in psychophysiology (Vol. 2, pp. 1-78). Greenwich, CT: JAI Press.

halgren, E., Squires, N., Wilson, C., Rohrbaugh, J., BabB, T., \& Crandall, P. (1980). Endogenous potentials in the human hippocampal formation and amygdala by infrequent events. Science, 210, 803-805.

Johnson, R., \& DonchIN, E. (1978). On how P300 amplitude varies with the utility of the eliciting stimuli. Electroencephalography \& Clinical Neurophysiology, 44, 427-438.

Johnson, R., Pfefferbaum, A., \& Kopell, B. S. (1985). P300 and longterm memory: Latency predicts recognition performance. Psychophysiology, 22, 447-507.

Kramer, A., Schneider, W., Fisk, A., \& Donchin, E. (1986). The effects of practice and task structure on components of the event-related brain potential. Psychophysiology, 23, 33-42.

LADISH, C., \& PouCH, J. (1989). P300 and probability in children. Journal of Experimental Child Psychology, 48, 212-223.

McCarthy, G., Wood, C. C., Williamson, P. D., \& SPENCER, D. D. (1989). Task-dependent field potentials in human hippocampal formation. Journal of Neuroscience, 9, 4253-4268.

Michaelewski, H. J., Prasher, D. K., \& STARR, A. (1986). Latency variability and temporal interrelationships of the auditory event-related potentials (N1, P2, N2, and P3) in normal subjects. Electroencephalography \& Clinical Neurophysiology, 65, 59-71.

Paller, K. A., McCarthy, G., \& Wood, C. C. (1988). ERPs predictive of subsequent recall and recognition performance. Biological Psychology, 26, 269-276.

Pfefferbaum, A., \& Rosenbloom, M. (1987). Skull thickness influences P3 amplitude. Psychopharmacological Bulletin, 23, 493-496.

Pouch, J. (1986a). Normal variation of P300 from auditory stimuli. Electroencephalography \& Clinical Neurophysiology, 65, 236-240.

Polich, J. (1986b). P300 development from auditory stimuli. Psychophysiology, 23, 590-597.

PoLICH, J. (1987b). Task difficulty, probability, and inter-stimulus inter$\mathrm{val}$ as determinants of $\mathrm{P} 300$ from auditory stimuli. Electroencephalography \& Clinical Neurophysiology, 68, 311-320.

PouICH, J. (1989a). Habituation of P300 from auditory stimuli. Psychobiology, 17, 19-28.

PoLICH, J. (1989b). Neuroanatomical contributions to individual differences in P300 morphology. In E. Basar \& T. H. Bullock (Eds.), Brain dynamics: Progress and perspectives (pp. 331-338). Berlin: SpringerVerlag.

Polich, J., \& BuRns, T. (1987). P300 from identical twins. Neuropsychologia, 25, 299-304.

Polich, J., HowARD, L., \& STARR, A. (1983). P300 latency correlates with digit span. Psychophysiology, 20, 665-669.

Polich, J., LADISH, C., \& BLOOM, F. E. (1990). P300 assessment of early Alzheimer's disease. Electroencephalography \& Clinical Neurophysiology, 77, 179-189.

Pritchard, W. S. (1981). Psychophysiology of P300. Psychological Bulletin, 89, 506-540.

SKLARE, D. A., \& LYNN, G. E. (1984). Latency of the P3 event-related potential: Normative aspects and within-subject variability. Electroencephalography \& Clinical Neurophysiology, 59, 420-424. 